\title{
Investigating Flexibility and Information Technology as Key Elements for Competitive Advantage
}

\section{Guilherme Guedes Xavier}

Boston University

\begin{abstract}
"Time" has been appointed as a new source of Competitive Advantage (CA) and following this trend flexibility, that is deeply related to quick responses for changes in the environment, becomes a key element for CA. Using survey data collected from 212 manufacturing companies in US, we investigate the importance of flexibility and Information Tectnology (IT) as major elements in achieving CA. We identify CA from performance measures related to market growth, market share and profitability. Flexibility is evaluated using manufacturing and product development perspectives, emphasizing changes in these two business functions. The study also looks at the relationship between the integration of Information Systems (IS) and introduction of Information Technology (IT), and key variables for CA. The results support the hypothesis that flexibility is related to the measures of $\mathrm{CA}$ and show that IS/IT is primarily related to the service dimension.
\end{abstract}




\section{Introduction}

Managers world wide strive to lead their companies in achieving Competitive Advantage (CA). However, identifying the key elements for achieving $\mathrm{CA}$ is a complex task. Recently different authors, including scholars and practitioners, have pointed out the shifts in the key elements regarded as important for CA. Some authors, like Harrigan (1985), Stalk (1988), Keen (1988) and Versey (1992), have argued that companies and organizations are becoming "Time Competitors" and that flexibility is a new key element for CA.

Over the years, the concept of flexibility has been defined in different ways (e.g. Slack, 1983; DeMeyer et. al, 1989; Ferdows and DeMeyer, 1990; Sethi and Sethi, 1990; Upton, 1994; Suarez et al., 1995). In this paper we conceptualize flexibility as the ability to adapt quickly to changes in volumes of demand, in product mix and in product design. Based on this definition, we address the investigate the claim of flexibility as a key element for CA by analyzing the data collected by the Manufacturing Future Survey from Boston University. We develop our framework based on the existing literature and test the hypothesis that flexibility is a key element to achieving $\mathrm{CA}$ in the US manufacturing industry. We also extend this study to analyze the importance of Information Systems (IS) and Information Technology (IT) to flexibility and other important elements for $\mathrm{CA}$, such as quality, price and service.

\section{Theoretical Framework}

Porter (1985) has pointed out that CA grows from the value a firm is able to create for its buyers, that exceeds the firm's cost of creating it. Value is what buyers are willing to pay for what a firm provides them. Superior value comes from offering lower prices than competitors for the same benefits, called cost leadership, or providing unique benefits that more than offset a higher price, called differentiation. Value is measured by total revenue, and a firm is profitable if the value it commands exceeds the costs involved in creating products. It is important to use value, instead of cost, for analyzing competitive advantage because firms often deliberately raise their cost in order to obtain a premium price via differentiation.

Considering Porter's ideas, some authors have discussed various ways for achieving cost leadership and differentiation (Garvin, 1988; Hayes and Wheelwright, 1988; Hill, 1993; Youndt et al. , 1996). For example, in his study comparing US and Japanese firms in different industrial sectors, Garvin has concluded that quality was an important factor for Japanese firms in achieving CA (differentiation) in world markets. In fact, the search for CA in the 70' $s$ and in the 80 ' $s$ was deeply shaped by the emphasis on quality as a source of differentiation. This was the result of the tight competitive 
environment that emerged from the oil crisis. However, in the late 80's, authors like Keen (1988) and Stalk (1988), have noticed a switch in the relative importance of the sources of CA. These authors argued that due to the emphasis in quality during the past years, leading firms had already achieved such high levels of "product conformance" that they had come to a point where quality was no longer a problem, although still an important priority (Gerwin, 1996). Looking at empirical evidence from what these authors thought were reliable and durable trends, they predicted that the next source of CA would be Time. In other words, firms looking for CA should be able to reduce dramatically their lead times at different points of the value chain. As a result, flexibility would become a key element of CA (Slack, 1983; Harrigan, 1985, DeMeyer et al, 1989, Upton, 1995).

In this study, we follow these ideas and assess empirically the validity of this hypothesis by investigating the relative importance of flexibility among other sources of CA. Although these ideas are commonly accepted by practitioners, we argue that they have not yet been systematically assessed in empirical terms in the Operations Management (OM) and Industrial Engineering (IE) literature. As a matter of fact, most of the theory building in the field of OM has used the narrative approach (i.e. case-based tradition of business policy) and the classificatory approach (i.e. development of strategy classifications based on typologies), rather than the comparative approach (i.e. based on empirical comparison and evaluation). The testing of theoretical frameworks is an ubiquitous part of the ongoing process of theory building (Bagozzi and Philips, 1982), and this study presents a contribution to the concept of $\mathrm{CA}$ by providing a more rigorous and empirical assessment of its theory.

It is important to notice that besides flexibility, quality, service and price have also been proposed as important sources of CA (Garvin, 1988; Hayes and Wheelwright, 1984; Milar and Porter, 1985; Powel, 1995). However, based on the increasing complexity of competitive environments (Stalk, 1988) in this study we hypothesize that flexibility will show up as a the most important variable (HO1).

In the second stage of our study, we are interested in how IT is associated to flexibility. Flexibility depends on how well different activities are integrated within firms (i.e., theories of governance Willianson, 1975) and how well information is exchanged among groups (i.e., information processing theories Galbraith, 1973; Simon, 1977; Tushman and Nadler, 1978). Thus, it can be increased by improving channels of communication through the development of IS. Following Gurbaxani and Whang (1991), who point out that modern IT can reduce the costs of communication and 
can improve the quality and speed of information processing, we posit that $I T$ is positively related to flexibility (HO2).

\section{Methods}

The analysis presented in this paper was conducted using data provided by the US section of the 1994 Manufacturing Future Survey, which portrays the collective perceptions of industry leaders about strategic goals, programs and performance trends in manufacturing firms (Kim and Frolhick, 1994).

The Manufacturing Futures Survey was initially developed at Boston University in 1981. Since the early 1980s this survey has been administered by an international team of researchers from the Boston School of Management, INSEAD in Fountainebleau, France and Waseda University in Tokyo, Japan. Beginning in 1990 , the survey has been conducted every two years. In 1994, over 1000 executives from medium to large manufacturing firms from eighteen nations including Japan, China, Korea, Singapore, Taiwan, Australia, New Zealand, Mexico and US participated in the study.

The various versions of the survey employed over the years have contained two types of questions. The baseline or core questions have appeared virtually unchanged in every version of the survey in every country since 1982. The non-core questions have been included in the survey to gather data related to particular hypotheses or to gather data that are significant for a particular nation (Kim and Frolhick, 1994).

The 1994 US Manufacturing Futures Survey used in this study was a thirteen page questionnaire with over three hundred individual questions designed to be answered by a senior manufacturing executive of the responding business unit. The non-core questions, included in the 1994 survey, addressed issues regarding global operations and new product development. The 1994 survey was sent by mail with a personally addressed letter to 1009 potential informants. One month later, a follow up letter was sent to those who had not responded by that time. A survey " hotline" was maintained to answer by phone call or mail any questions informants had about the survey. Two months later each non-respondent was reminded by another follow-up letter. At the end of the fourth month the survey data was consolidated and 212 valid responses had been encoded. The response rate was $21 \%$, which is considered satisfactory for the type of survey conducted (Gaedke and Tootelian, 1976)

\section{Participating Firms}

Potential participants were drawn from three panels : A, B and C. Table 1 presents the response rates. Panels $A$ and $\mathrm{B}$, together, accounted for 334 names, which were drawn from the Fortune 500 listing, and supplemented by lists of senior manufacturing participants in various 
Boston University executive programs. Panel A (149 members) included companies which had provided data to the survey at least once in either 1990 or 1992. The response rate from this group was over 40 percent and they are an important source for longitudinal studies. Panel B included previous non-respondents, as well as the names of individuals who had attended Boston University executive programs on Manufacturing Strategy. The response rate for panel B was over 20 percent. Panel $\mathrm{C}$ was proportionally drawn, by two digit SIC codes, from a commercially available list of leading US firms by industry, which are not in the Fortune 500. The response rate for this panel was over 15 percent (Kim and Frohlick, 1994).

\begin{tabular}{|ccc|}
\hline Panel & $\begin{array}{l}\text { Number of } \\
\text { surveys sent }\end{array}$ & Response rate \\
\hline A & 149 & $40 \%$ \\
B & 185 & $20 \%$ \\
C & 675 & $15 \%$ \\
\hline Total & 1009 & $21 \%$ \\
\hline
\end{tabular}

Table1

Respondents rate among different groups

Within the sample, the average number of employees is 4700 (SD $=$ 7914). The predominant group by industrial category (i.e. industrial or consumer goods) is industrial goods (75 $\%$ ), $80 \%$ of the companies have discrete production flow and the rest $20 \%$ have continuous production flow.

\section{Measures}

Our hypotheses were tested using different scales for each of the constructs we were interested in. We used performance measures as indicators for CA. This is according to Porter (1985), who has pointed out that "the fundamental basis of above-average performance in the long run is sustainable competitive advantage" (p. 11), thereby making a direct link between $C A$ and performance measures. Performance measures of market share and profitability were based on a performance index for each respondent. The beginning of 1991 was chosen as the baseline year (value of index $=100$ ). Informants were asked to assign the relative value to each indicator as of the end of the year 1993. An index greater than 100 indicates improvement, while an index less than 100 indicates worse performance. For the other performance measure, market growth, informants were asked to provide the percentage of increase over the previous year.

Quality, service, manufacturing flexibility and new product development flexibility indicators were based on MFP multi-item scales for these constructs (Kim and Frohlick, 1994). For specific points associated to each construct, informants were asked to evaluate their strength relative to their best competitors. Answers were given on a 7 point, self anchoring scale, where $1=$ much weaker and $7=$ much stronger. The reliability for each scale was measured using the Cronbach alpha index and all results were 
above the acceptable value of 0.60 (Nunnally, 1978). The scale for quality had four items and the reliability was 0.84 . The scale for service had two items and the reliability was $\mathbf{0 . 8 3}$. The Cronbach alpha for manufacturing flexibility was 0.78 and for new product development flexibility, 0.69. Both scales had two items each. We used the overall score (sum of the items) for each scale as a measure of the firm's capability.

Finally, the scale for IS/IT was based on the success of programs associated with improving the effectiveness of operations such as $\mathrm{CAD} / \mathrm{CAM}$ integration, IS for production planning and control, crossfunctional IS. In the questionnaire we identified 5 items associated with the relative payoff of IT/LS programs/activities during the last two years. Answers were given on a 7 point, self anchoring scale where $1=$ little pay-off and $7=$ great payoff. The reliability, tested by Cronbach alpha, was 0.75 . We used the sum of the five items as the measure for IT use.

\section{Results}

Descriptive statistics are presented in Table 2, and the correlation matrix of all variables used in the analysis is presented in Table 3. The average score for product flexibility is $8.4(\underline{S D}=1.97)$ and for manufacturing flexibility is 9.27 $(\underline{\mathrm{SD}}=2.08)$. The average score for service is $9.40(\mathrm{SD}=2.14)$ and for quality is 19.54 $(\underline{\mathrm{SD}}=3.76)$. The average score for IS/IT is $24.68(\underline{\mathrm{SD}}=24.68)$. The average score for price strength is $4.27(\mathrm{SD}=1.25)$. The average score for market growth is 107.48 $(\mathrm{SD}=10.51)$. The average score for market

\begin{tabular}{ccccccc}
\hline Variables & M & SD & Min & Max & n & $\begin{array}{c}\text { Cronbach } \\
\text { alpha }\end{array}$ \\
Product flexibility & 8.54 & 1.97 & 3.00 & 14.00 & 208 & 69 \\
$\begin{array}{c}\text { Manufacturing } \\
\text { flexibility }\end{array}$ & 9.27 & 2.08 & 3.00 & 14.00 & 209 & 78 \\
Quality & 19.54 & 3.76 & 10.00 & 28.00 & 203 & 84 \\
Service & 9.40 & 2.14 & 3.00 & 14.00 & 206 & 83 \\
IS/TT & 24.68 & 5.77 & 11.00 & 42.00 & 147 & 75 \\
Price strengh & 4.27 & 1.25 & 1.00 & 7.00 & 209 & - \\
Market growth & 107.48 & 10.51 & 60.00 & 140.00 & 171 & - \\
Market share & 107.84 & 15.81 & 50.00 & 175.00 & 199 & - \\
Profitability & 116.81 & 41.91 & 10.00 & 400.00 & 200 & - \\
\hline
\end{tabular}

Table 2

Descriptive Statístics for Scale Scores and Single items 


\section{PRODUÇÃO}

share is $107.84(\underline{S D}=15.51)$ and the average score for profitability is $\mathbf{1 1 6 . 8 1}$ $(\underline{S D}=41.91)$.

Two outliers were discarded from the data about market growth, five were discarded from the data about profitability and four were discarded from the data about manufacturing flexibility. There were $223(10.52 \%)$ missing data points, out of a total of 2120 . Missing data were randomly distributed throughout most of the data matrix, except for the construct IS/IT where the percentage was greater $(30.66 \%)$ than the other scales. As will be discussed later, these results pose some limitations for the interpretation of results associated to this construct (internal validity). No other abnormalities in the data, regarding the measures, were found. All analysis were made considering levels of significance at $p=0.05$

\section{Hypothesis Testing}

We found a statistically significant and positive relationship between product flexibility and two measures of CA : market share $(r=0.16, \underline{p}<0.05)$ and profitability $(r=0.23, \mathfrak{p}<0.05)$. We also found a statistically significant and positive relationship between manufacturing flexibility and profitability $(r=0.14, p<0.05)$, as hypothesized. However, the relationships between market growth and product or manufacturing flexibility were not significant. The results are presented on Table 3.

In the regression analysis for predicting market share (Table 4), none of the proposed sources of CA were found significant at $p=0.05$. However product flexibility and quality were significant at

\begin{tabular}{lllllllll}
\hline Variables & 1 & 2 & 3 & 4 & 5 & 6 & 7 & 8
\end{tabular}

\begin{tabular}{|c|c|c|c|c|c|c|c|}
\hline 1.Market & - & & & & & & \\
\hline 2.Market & $0.30^{*}$ & - & & & & & \\
\hline 3. Profitability & 0.12 & $0.37 *$ & - & & & & \\
\hline flexibility & 0.01 & $0.16^{*}$ & $0.23 *$ & & & & \\
\hline $\begin{array}{l}\text { 5. Manufacturing } \\
\text { flexibility }\end{array}$ & 0.04 & 0.11 & $0.14^{*}$ & $0.26 *$ & - & & \\
\hline 6. Quality & 0.11 & $0.14^{*}$ & 0.09 & -0.07 & -0.02 & - & \\
\hline 7. Service & 0.02 & 0.09 & 0.06 & 0.00 & 0.07 & $0.60 *$ & - \\
\hline 8. Pric & 0.01 & 0.12 & 0.04 & 0.04 & 0.02 & $0.21 *$ & $0.19 *$ \\
\hline
\end{tabular}

Table 3

Intercorrelation between meassures of $\mathbf{C A}$ and sources of $\mathbf{C A} \mathrm{p}^{*}<0.05 \mathrm{p}^{* *}, 0.10$ 


\section{PRODUÇÃO}

$p=0.10$. As a result, since we are using a more conservative approach $(p=0.05)$ we concluded that product flexibility, though positively related to market share, is not a significant predictor for market share. Using the regression model, we were also unable to differentiate the importance of product flexibility among other variables, since none were statistically significant.

In the regression model for predicting profitability (Table 5), product flexibility was significant $(\underline{B}=0.30, \underline{p}<0.05)$. However, R-square is only 0.08 , which means that product flexibility alone is not strong enough to predict profitability. In the regression model for predicting market growth (Table 6), none of the variables was statistically significant at $p$ $=0.05$. However, once again quality was significant at $\mathbf{p}=\mathbf{0 . 1 0}$.
The second part of this study investigates the relationship between IS/ IT and flexibility. As presented in Table 7, the only variable related to IS/IT that was statistically significant was service $(\underline{r}=0.20, \underline{p}<0.05)$. Thus the second hypothesis was not supported (HO2).

\section{Discussion}

In this study we found evidence that product flexibility is positively related to CA, measured in terms of market share and profitability. We also found evidence that manufacturing flexibility is positively related to $\mathrm{CA}$, measured as profitability. Notice that no other source of CA was found to be statistically significant as related to measures of $\mathrm{CA}$. These results support the findings in the literature (Keen , 1988; Stalk, 1988; Harrigan, 1985) and the first hypothesis (HOl).

\begin{tabular}{cccc}
\hline Variables & $\underline{\text { B }}$ & $\underline{\text { SE B }}$ & Beta \\
$\begin{array}{c}\text { Product } \\
\text { flexibility }\end{array}$ & 0.06 & 0.03 & $0.14 * *$ \\
$\begin{array}{c}\text { Manufacturing } \\
\text { flexibility }\end{array}$ & 0.03 & 0.02 & 0.11 \\
Quality & 0.88 & 0.52 & $0.16^{* *}$ \\
Service & -0.10 & 0.91 & -0.01 \\
Price & 1.18 & 1.25 & 0.07 \\
\hline
\end{tabular}

note: $R^{2}=0.07 p^{* *}<0.10$

Table 4

Summary of Standard Regression Analysis for Sources of CA Predicting Market Share 
Variables

Product flexibility

Manufacturing flexibility

Quality

Service

Price

B

$\underline{\text { SE B }}$

Beta

note: $R^{2}=0.08 p^{*}<0.05$

Table 5

Summary of Standard Regression Analysis for Sources of CA Predicting Profitability

\begin{tabular}{cccc}
\hline Variables & B & SE B & Beta \\
$\begin{array}{c}\text { Product } \\
\text { flexibility }\end{array}$ & 0.00 & 0.02 & 0.01 \\
$\begin{array}{c}\text { Manufacturing } \\
\text { flexibility }\end{array}$ & 0.01 & 0.02 & 0.05 \\
Quality & 0.79 & 0.43 & $0.20 * *$ \\
Service & -0.51 & 0.72 & -0.08 \\
Price & -0.67 & 0.99 & -0.06 \\
\hline
\end{tabular}

note: $R^{2}=0.03 p^{*}<0.10$

Table 6

Summary of Standard Regression Analysis for Sources of CA Predicting Market Growth 


\section{PRODUÇÃO}

\begin{tabular}{lcccccc}
\hline Variables & 1 & 2 & 3 & 4 & 5 & 6 \\
$\begin{array}{l}\text { Product } \\
\text { flexibility }\end{array}$ & - & & & & \\
2. Manufacturing & $0.26 *$ & - & & & \\
flexibility & -0.07 & -0.02 & - & & \\
3. Quality & 0.00 & 0.07 & $0.60 *$ & - & - \\
4. Service & 0.04 & 0.02 & $0.21 *$ & $0.19 *$ & -0.02 \\
5. Price & 0.06 & 0.03 & $0.14 * *$ & $0.20 *$ & - \\
6. IS/IT & & & & & \\
\hline
\end{tabular}

$\mathrm{p}^{*}<0.05 \mathrm{p}^{* *}<0.10$

Table 7

Intercorrelation between measures of $\mathrm{CA}$ and sources of $\mathrm{CA}$

It is also interesting to notice that product flexibility contributes more to $\mathrm{CA}$ than manufacturing flexibility, and there are some explanations for this finding in our study. One possible explanation is that the data analyzed is only for the US section of the MFS. If other countries such as Japan had been included, the results would probably have been different. The Japanese industry is recognized worldwide as being very flexible at the shop floor level, as well as at the product development level (Wheelwright, 1981; Garvin, 1988). Techniques like Single Minute Exchange of Dies (SMED), kanban systems, just-in-time deliveries (Schonberger, 1982, Monden, 1983; Shingo, 1988) are widely used in Japanese companies and appear to represent sources of CA for those companies. For example, while comparing Japanese companies and US companies, Kim and Frohlick (1994) have pointed out that the percentage of on-time deliveries in Japanese companies that participated in the 1994 MFS is 95.9 $\%$, compared to $88.9 \%$ for US companies.

On the other hand, it is important to recognize the importance of product development in a competitive market, and this was anticipated in the design of the 1994 MFS, which introduced a series of items related to product development in the non-core questions.

Another important result in the first part of the study is the low value of predictive power associated with the regression model for predicting profitability $(\underline{R}$-square $=0.08)$. This shows that identifying key elements for achieving $\mathrm{CA}$ is a very complex task, since there is a large number of factors involved, and these factors are likely to change over time. For example, Millar and Porter (1985) pointed out that new technologies, 


\section{PRODUÇÃO}

such as IT, are able to change industry structures and spawn whole new businesses, thereby transforming the entire value chain. The low value ofsquare indicates that many other factors besides product flexibility have to be taken in account to predict CA. As a practical implication, managers should be careful when evaluating different manufacturing strategies and making decisions (Hayes and Wheelwright, 1988; Hill, 1993)

The second hypothesis (H02), was not supported and there can be several reasons. First there was a large number of missing data in the IS/IT scale, which may have introduced bias. Another possible explanation, which may hold as an overall limitation to the study is related to the nature of the scales used. The MFS is a very broad survey (over 300 questions) with different constructs addressed at the same time. With the core questions, the survey intends to capture a high level of generality, instead of specificity. On the other hand, in this study we are looking for specific relationships between IS/IT and flexibility. A survey designed for such a specific relationship would probably have produced higher internal validity and supported the hypothesis. In special, in this study which focus on manufacturing firms, it would be interesting to use the concept of Advanced Manufacturing Technologies (AMT) to operationalize the construct IS/IT. As pointed out by Dean and Snell (1996) AMT are seen as the manufacturing subset of Information Technology.
A third explanation would be that in fact IS/IT, or at least the indicators IT/IS captured in this study are not the most important drivers of flexibility. Youndt et. al (1996) have studied Human Resources management and manufacturing performance, and pointed out that current research findings have shown that manufacturing flexibility depends much more on people than on technical factors per se. A whole stream of research in Operations Management and Industrial Engineering, that focus on employee involvement, team working and continuous improvement (TQM), has also produced similar findings.

Although IS/IT was not statistically significant related to flexibility, we found that it was significantly related to service $(\mathrm{r}=0.20, \mathrm{p}<0.05)$. This is an insightful result, because if we look deeper into the nature of service activities (Lovelock, 1983; Kendrick, 1985; Wemmerlov, 1990), we note that services are very dependent on good channels of communication. Service activities in the value chain of manufacturing firms provide direct links from companies or distribution channels (retailers) to customers (Cohen and Lee, 1989; Geoffrion and Powers, 1995). Due to this nature of service activities, one would certainly argue that IS/IT, which can improve channels of communication, should indeed be related to service.

Besides the stated hypotheses, other interesting results were also found in this study. The contribution of the number of 
employees, industry categories and production system on measures of CA, were found to be significant (Table 8). The same characteristics were analyzed for their relationships with sources of CA (Table 9). The only statistically significant relationship was between industry category and service. This is expected, since firms were categorized into consumer goods and industrial goods companies. Although service is an activity present in both categories, the nature of service provided is completely different for each : consumer goods companies provide service to their customers through distribution channels (retailers), while industrial goods companies usually provide service to their customers directly.
The limitations of this study are as follows. First, the sample is not fully representative for the manufacturing companies population because we did not have control over its distribution. Another issue is that the overall response rate was $21 \%$ and it varied widely from the first $(40 \%)$ to the last group (15\%). This can bring potential sources of bias to the survey. Therefore, it is important to compare differences among the three samples to make sure that they can be combined.

Another limitation, which was discussed earlier in this study, is the generality of the survey. When trying to establish specific linkages between
Variables

1. Market growth

2. Market share

3. Profitability

4. Number of employees

5. Industry category

$-0.10$

$-0.06$

$-0.11$

$-0.03$

6. Production system

\subsection{2 \\ $0.37 *$}

$-0.04$

$-0.03$
4

5

6

$\mathrm{p}^{*}<0.05 \mathrm{p}^{* *}<0.10$

\section{Table 8}

Intercorrelation between measures of $\mathrm{CA}$, number of employees, industry category and production system 
specific constructs, a more customized survey is desirable. A fourth limitation is related to the nature of the data collected by the MFS. The questionnaire is designed to be answered by senior executives in the manufacturing business unit. This is in accordance to Venkatraman and Grant (1986), who argue that while conducting research at the organizational level, one should look for the most representative and knowledgeable informants to provide information about organizational properties. MFS survey informants were encouraged to provide institutional and more objective information, like catalogs, brochures and reports, in order to allow further analysis. However, the basic data used in this study were data provided by the senior manager (scales), which are subjective and portrays their perceptions (Kim and Frohlick, 1994),. In order to guarantee maximum validity we should employ triangulation approaches (Jick, 1979) to achieve a balance between perceived data and more objective data.

Finally, the measures of CA used in this study pose some limitations and threats for internal validity. As discussed before, CA is a well accepted concept, but its operationalization is not straightforward. The study used performance measures such as market share, market growth and profitability as surrogate measures for $\mathrm{CA}$. This is supported by the literature (Porter, 1985), but we acknowledge that other unexplored measures may exist

Overall the study presents some important information about sources of $\mathrm{CA}$ for manufacturing companies.

\begin{tabular}{|c|c|c|c|c|c|c|c|c|}
\hline Variables & 1 & 2 & 3 & 4 & 5 & 6 & 7 & 8 \\
\hline $\begin{array}{l}\text { Produca } \\
\text { flexibility }\end{array}$ & - & & & & & & & \\
\hline $\begin{array}{l}\text { 2. Manufaduring } \\
\text { flexibility }\end{array}$ & $0.26^{\circ}$ & - & & & & & & \\
\hline 3. Quality & .0 .07 & .0 .02 & - & & & & & \\
\hline 4. Service & 0.00 & 0.07 & $0.60^{*}$ & - & & & & \\
\hline 9. Price & 0.04 & 0.02 & $0.21^{*}$ & 0.19 & - & & & \\
\hline $\begin{array}{l}\text { 6. Number of } \\
\text { em ployees }\end{array}$ & 0.11 & -0.02 & 0.06 & $0.144^{\circ}-1-10$ & .0 .01 & -0.03 & - & \\
\hline 7. Industry caltegory & -0.02 & -0.02 & 0.06 & $0.14^{\circ}$ & -0.01 & -0.03 & & \\
\hline $\begin{array}{l}\text { 8. Production } \\
\text { system }\end{array}$ & 0.00 & .0 .11 & .0 .05 & -0.01 & $0.11 * *$ & 0.06 & $-0.12 * *$ & \\
\hline
\end{tabular}

$\mathrm{p}^{*}<0.05 \mathrm{p}^{* *}<0.10$

\section{Table 9}

Intercorrelation between sources of $\mathbf{C A}$, number of employees, industry category and production system 


\section{PRODUÇÃO}

Although there are certain limitations in this study regarding the sample, the empirical results can be used by practitioners in the manufacturing industry when looking for potential directions to achieve CA. The study also contributes to academic research because it is based on theory and the empirical results are according to the theory. Thus, following the tradition of cumulative theory building and theory testing, these empirical results can be taken as a departure point for new research in the domain of CA and IS/IT. For example, the relationship between IS/IT and service, found in this study, should be further explored. At the same time, better scales could be developed and further studies could be conducted to investigate the relationship among IT/IS, flexibility and human resources management.

\section{References}

Bagozzi, R. P. and L. W. Phillips (1982). "Representing and testing organizational theories: A holistic construal." Administrative Science Quarterly 27: 459-489.

Cohen, M.S and Lee, H.L. (1989). Resource Deployment Analysis of Global Manufacturing and Distribution Networks. Journal of Manufacturing and Operations Management, Vol. 2, pp. 81104.

Dean, James $\mathrm{W}$ and Snell, Scott (1996) The strategic use of integrated manufacturing : An empirical examination, Strategic Management Journal, vol. 17, pg. 459-480

DeMeyer, A., Nakane, J., Miller J., \& Ferdows, K. 1989. Flexibility: The next competitive battle. Strategic Management Journal, 10: 135-144.

Ferdows, K. and de Meyer, A., (1990) "Lasting improvement in manufacturing" , Journal of Operations Management, Vol. 9 No. 2, pp. 168-184.

Gaedke, P. M. and D. H. Tootelian (1976) The fortune 500 list : An endangered species for academic research. Journal of Business Research, vol. 4, pg., 283-288

Galbraith, J. (1973). Designing complex organizations. Reading, MA: Addison-Wesley.

Garvin, David. A. (1988). Managing quality: the strategic and competitive edge. London : Collier Macmillan.

Geoffrion, A.M. and Powers, R.F. (1995). Twenty Years of Strategic Distribution System Design: An Evolutionary Perspective. Interfaces, Vol. 25, No. 5, pp. 105-127.

Gerwin, Donald (1996) Manufacturing flexibility: A strategic perspective, Management Science, vol. 39 , no 4 , pg. $395-410$ 
Grant, Robert M; Shani, Rami; Krishnan, R (1994). TQM's challenge to management theory and practices. Sloan Management Review, vol. 35, pp. 25-35

Gurbaxani, Vijay \& Whang, Seungjin (1991). The impact of information systems on organizations and markets. CACM, vol. 34 , no I, pp. 502-527

Harrigan, Kathryn R. (1985). Strategic Flexibility : a management guide for changing times. Lexington, Mass : Lexington Books.

Hayes, R.H. and Wheelwright, S.C., Restoring Our Competitive Edge, Collier Macmillan, New York, NY, 1984.

Hayes, R. H., Wheelwright, S. C., \& Clark, K. B. 1988. Dynamic manufacturing: Creating the learning organization. New York: Free Press.

Hill, T.J., Manufacturing Strategy: The Strategic Management of the Manufacturing Function, 2nd ed., Macmillan, London, 1993

Jick, T. (1979). "Mixing Qualitative and quantitative methods: Triangulation in action." Administrative Science Quarterly 24(December): 602-611.

Keen, Peter. G. W (1988). Competing in time: Using telecommunications for competitive advantage. Cambridge, Mass : Ballinger.
Kendrick, J. W. (1985). Measurement of Output and Productivity in the Service Sector. Managing the Service Economy. E. P. Inman. Cambridge, MA, University Press: 111-123.

Kim, S. J. and Frohlich, M. T. (1994). The 1994 Manufacturing Futures International Fact Book. Boston University, research report.

Lovelock, C. H. (1983). "Classifying Services to Gain Strategic Insights." Journal of Marketing 47: 9-20.

Millar, V. and Porter, M (1985). How information gives you competitive advantage. Harvard Business Review, vol. 63, no. 4, pp. 149-160.

Miller, J.G. and Roth, A.V., (1994) "A taxonoour of manufacturing strategies", Management Science, Vol. 40 No. 3, pg. 285.304.

Monden, Y. (1983), Toyota Production System : Practical Approach to Production Management, Industrial Engineering and Management Press.

Nunnally, J. C. 1978. Psychometric theory. New York: McGraw-Hill.

Powel, Thomas C. (1995). Total quality management as competitive advantage : a review and empirical study. Strategic Management Journal, vol. 16, pp. 15-37. 


\section{PRODUÇÃO}

Porter, Michael. E. (1985). Competitive advantage : Creating and sustaining superior performance. New York : Free Press

Schroeder, R. G., Anderson, J. C., \& Cleveland, G. 1986. The content of manufacturing strategy: An empirical study. Journal of Manufacturing, 6: 405415 .

Shingo, Shigeo (1988). The Toyota System : from an Industrial Engineering point of view. Productivity Press, Mass

Simmon, H. A. (1977) Administrative Behavior, Mcmillan, New York

Sethi A.K. and P.S. Sethi, (1990): “ Flexibility in Manufacturing: A Survey " International Journal of Flexible Manufacturing Systems, vol. 2, pg. 289328 ;

Slack, N. (1983): "Flexibility as a Manufacturing Objective," International Journal of Production Management Vol. 3, no 3, pg. 4-13;

Stalk, George (1988). Time : The next competitive advantage. Harvard Business Review, vol. 66, pp. 41-51.

Suarez, Fernando F; Cusumano, Michael A; Fine, Charles H (1995) An empirical study of flexibility in manufacturing, Sloan Management Review, Vol. 37, No. 1 Pg. 25-32
Tang, Victor. (1995). Competitive dominance : Beyond strategic advantage and total quality management. New York : Van Nostrand Reinhold.

Tushman, M. L., \& Nadler, D. A. (1978). Information processing as an integrating concept in organizational design. Academy of Management Review, 3: 613-624.

Upton, D.M., (1994) “The management of manufacturing flexibility" , California Management Review, Vol. 36, No. 2 Pg. 72-89;

Upton, D. M.1995. What really makes factories flexible? Harvard Business Review, 73(4): 74-84.

Venkatraman, N. and J. H. Grant (1986). "Construct measurement in strategy research: A critique and proposal." Academy of Management Review 11: 71-86.

Venkatraman, N. (1989). "Strategic orientation of business enterprises: The construct, dimensionality and measurement." Management Science 35(8): $942-962$.

Vesey, Joseph T. (1992). The new competitors : They think in terms of speed to market. Production \& Inventory Management Journal, vol. 33, no 1, pp. 71-77.

Youndt, Mark A; Snell, Scott A; Dean, James W Jr; Lepak, David P (1996) 
Human resource management, manufacturing strategy, and firm performance, Academy of Management Journal, Vol. 39, No. 4 Pg. 836-866

Wemmerlov, U. (1990). "A Taxonomy for Service Processes and Its Implications for Systems Design." International Journal of Service Industry Management 1(3): 20-40.
Wheelwright, S. C.1981. Japan, where operations really are strategic. Harvard Business Review, 59(4): 67-74.

Williamson, O. E. (1975) Markets and hierarchies, Free Press, NY

\section{Acknowledgments}

The author grateful acknowledge professors Jay S. Kim from Boston University, US and Mark Frolich from the London School of Economics, UK for allowing him to access the data from the 1994 US Manufacturing Future Survey. The author would also like to thank the assistance from professors Lee Sproull from Boston University, US and Alain Villeneuve from University of Sherbrook, Canada for their comments and suggestions in a first version of this paper. Finally, the author would like to acknowledge the support received from the Brazilian Agency of Post-Graduate Studies - CAPES under the grant no 058-94-02 